Scientific Review Engineering and Environmental Sciences (2022), 31 (1), 63-76

Sci. Rev. Eng. Env. Sci. (2022), 31 (1)

https://srees.sggw.edu.pl

Nguyen Minh NGOC ${ }^{1 \bowtie}$ iD https://orcid.org/0000-0002-2664-5558

Pham Hong CUONG ${ }^{2}$

Tran Thanh SON ${ }^{1}$

Nguyen Van NAM $^{1}$

Nguyen Thanh PHONG ${ }^{1}$

${ }^{1}$ Hanoi Architectural University, Vietnam

${ }^{2}$ Vietnam Academy for Water Resources (KLORCE), Vietnam

\title{
EXPERIMENTAL STUDY OF THE HYDRAULIC JUMP LENGTH IN A SMOOTH TRAPEZOIDAL CHANNEL
}

Key words: jump length, roller length, hydraulic jump, trapezoidal channel, spillway

\section{Introduction}

A hydraulic jump is a phenomenon that occurs in an open flow when the flow depth expands suddenly from less than the critical depth to greater than the critical depth (Chow, 2009). The jump in practice has many applications, such as energy dissipation of the flow, sludge thickening unit of water treatment system or water oxygen saturation by mixing air into water etc.
The jump is characterized by three basic parameters, which are the conjugate depths $\left(y_{1}, y_{2}\right)$ and the jump length. The jump length is distinguished by the length of the roller zone (Giglou, Giglou \& Minaei, 2013) and the estimated length of the jump (Movahed, Mozaffari, Davoodmaghami \& Akbari, 2018).

For rectangular channels, the length of the jump has been studied in many different cases, the equations for calculating the length are very plentiful and the equations have considered many factors affecting the length of the hydraulic jump. Meanwhile, research on the length of the jump in the isosceles trapezoidal channel is still few and studies are still limited, the studies are shown in Table 1. 
TABLE 1 . The studies of the jump length in the trapezoidal channel

\begin{tabular}{|c|c|c|}
\hline References & Equation & Characteristics \\
\hline Posey \& Hsing (1938) & $\begin{array}{l}L_{j}=5 y_{2}\left(1+4 \sqrt{\frac{T_{2}-T_{1}}{T_{1}}}\right) \\
\text { where } T_{i}=b+2 m \cdot y_{i}\end{array}$ & Trapezoidal channel, still basin. \\
\hline Silvester (1964) & $\begin{array}{c}\frac{L_{j}}{y_{2}-y_{1}}=7.1(1+10 M) \\
\text { where } M=\frac{m \cdot y_{1}}{b}<0.25\end{array}$ & Trapezoidal channel, still basin \\
\hline $\begin{array}{l}\text { Rajaratnam } \\
\& \text { Subramanya (1968) }\end{array}$ & $\begin{array}{l}\frac{L_{j}}{y_{1}}=5.08 F r_{1}-7.82 \\
\text { with } F r_{1} \geq 4.4\end{array}$ & Trapezoidal channel, still basin. \\
\hline Ohtsu (1976) & $\begin{array}{l}\log _{10}\left(\frac{L_{j}}{\Delta E}\right)=1.71 \eta+0.315 m+1.58 \\
\text { where } \Delta E=E_{1}-E_{2} \text { and } \eta=\frac{\Delta H}{E_{1}}\end{array}$ & Trapezoidal channel, still basin. \\
\hline $\begin{array}{l}\text { Wanoschek } \\
\text { \& Hager (1989) }\end{array}$ & $\frac{L_{j}}{y_{1}}=9.75\left(F r_{1}-1\right)^{1.01}$ & Trapezoidal channel, still basin. \\
\hline Afzal \& Bushra (2002) & $\begin{array}{l}\frac{L_{j}}{y_{2}}=6.9(1-\alpha) \\
\text { where } \alpha=\frac{y_{1}}{y_{2}}\end{array}$ & Trapezoidal channel, still basin. \\
\hline Kateb (2014) & $\begin{array}{l}\frac{L_{j}}{y_{1}}=9.58 F r_{1}-24.59 \\
\text { with }\left\{\begin{array}{l}3.46 \leq F r_{1} \leq 13.17 \\
-0.005 \leq i \leq 0.02 \\
0.031 \leq M \leq 0.093\end{array}\right.\end{array}$ & $\begin{array}{l}\text { Trapezoidal channel with angle of side } \\
\text { slope } 76.2^{\circ} \text { and bed width } 0.2 \mathrm{~m} \text {. }\end{array}$ \\
\hline Siad (2018) & $\begin{array}{l}\frac{L_{j}}{y_{1}}=9.97 F r_{1}-0.307 \\
\text { with }\left\{\begin{array}{l}2.09 \leq F r_{1} \leq 10.51 \\
0.0 \leq X_{i} \leq 1.0\end{array}\right. \\
X_{i} \text { is the distance from the toe of the jump to } \\
\text { the end of the trapezoidal channel. }\end{array}$ & $\begin{array}{l}\text { Trapezoidal channel with angle of } \\
\text { side slope } 73^{\circ} \text {, bed width } 0.2 \mathrm{~m} \text { and } \\
\text { length } L_{j \text { ref }}=4 \mathrm{~m} \text {. This channel is } \\
\text { continuous with rectangular channel } \\
\text { has dimension of a bed width } 0.6 \mathrm{~m} \\
\text { and length } 7 \mathrm{~m} \text {. }\end{array}$ \\
\hline $\begin{array}{l}\text { Fatehi Nobarian, Haji- } \\
\text { kandi, Hassanzadeh \& } \\
\text { Jamali (2019) }\end{array}$ & $\begin{array}{l}\text { Relationship diagrams between geometric } \\
\text { features }\left(L_{j} \text { and } y_{2} / y_{1}\right) \text { and energy of the jump } \\
\text { in the trapezoidal channel. }\end{array}$ & $\begin{array}{l}\text { Trapezoidal channel, still basin with } \\
\text { three types of side slopes }(1: 1 \text {, } \\
1: 0.58 \text { and } 1: 0.26) \text { and bed width } \\
0.2 \mathrm{~m}\end{array}$ \\
\hline
\end{tabular}


In this study, we are only focusing on analyzing the length of the jump after a spillway in the horizontal trapezoidal channel with a side slope $1: 1$ and upstream Froude number from 4.0 to 9.0 (steady jump).

\section{Analyzing factors affecting the jump length in the trapezoidal channel}

The momentum equation for the roller zone of the hydraulic jump, as flowing:

$F_{1}-F_{2}-F_{\tau}=M_{2}-M_{1}$

where:

$F_{1}, F_{2}$ - hydrostatic forces, $M_{1}, M_{2}-$ momentum fluxes,

(in which Subscripts 1 and 2 represent the upstream and downstream cross-section of the hydraulic jump, respectively).

Equation (1) has been shown in some studies about the hydraulic jump, such as the study of Palermo and Pagliara (2017), Movahed et al. (2018), in which integrated shear stress $\left(F_{\tau}\right)$ is determined as follows:

$F_{\tau}=\tau_{0} \cdot L_{r} \cdot \overline{\mathrm{P}}$

$\tau_{0}$-average shear stress between the two sections 1 and 2,

$L_{r}$ - roller length,

$\overline{\mathrm{P}}$ - averaged of wet perimeter between upstream and downstream sections.

Equation (2) was given by Frank (2016) and Movahed et al. (2018) shown in studies of the hydraulic jump.

According to $P_{i}$ theorem of Buckingham, using Equation (1) for the horizontal trapezoidal channel, it can be written:

$f\left(L_{r}, y_{1}, y_{2}, V_{1}, m, \rho, \mathrm{g}\right)$
From Equation (3) to write:

$$
\begin{aligned}
& \beta\left(\frac{L_{r}}{y_{1}}, \frac{y_{2}}{y_{1}}, \frac{b}{y_{1}}, m, F r_{D 1}\right) \\
& \Rightarrow \frac{L_{r}}{y_{1}}=\Phi\left(\frac{y_{2}}{y_{1}}, M_{1}, F r_{D 1}\right)
\end{aligned}
$$

Equation (5) is consistent with experimental studies on the jump length shown in Table 1. Thus, the data that needs to be collected on an experimental model for studying the jump length include the sequent depths $\left(y_{1}, y_{2}\right)$ and the flow rate $(Q)$.

\section{Experimental setup}

Experimental model was set up in the Vietnam Academy for Water Resources (KLORCE). The model consists of an ogee spillway, a straight-line trapezoidal channel is made of glass with the steel skeleton frame.

The experimental system (Figs. 1 and 2) is designed with the components:

- Experimental tank (1): The water is continuously supplied to the tank by a pump, with a supply flow equal to the flow over the spillway.

- Spillway (2): is an ogee spillway and the dimension of a $45 \mathrm{~cm}$ height, a $65 \mathrm{~cm}$ width and radius of the toe $R=1 \mathrm{~m}$. The water flows through the spillway (2) will create a supercritical flow, thereby making the jump in the trapezoidal channel (3).

- Trapezoidal channel (3): it has a smooth bed, $0.55 \mathrm{~m}$ width, $0.8 \mathrm{~m}$ depth and $0.4 \mathrm{~m}$ length with a side slope $m=1: 1$, it is placed horizontally and is set up with the cross-section shown in the section (1-1).

- Downstream step (4): This is a hole $20 \mathrm{~cm}$ deeper than the bottom of the channel, 


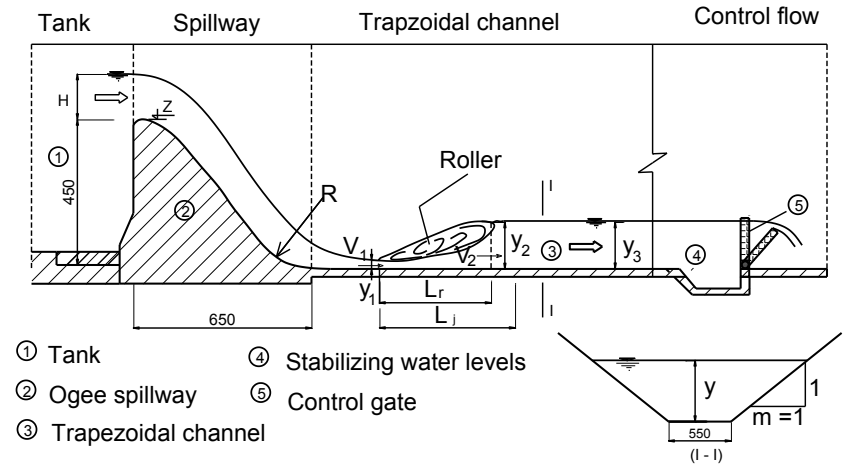

FIGURE 1. Plan of the experimental equipmen
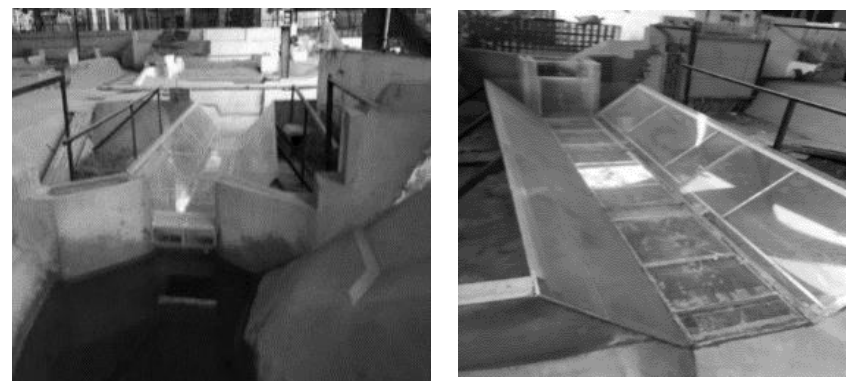

FIGURE 2. Panoramic view of experimental model
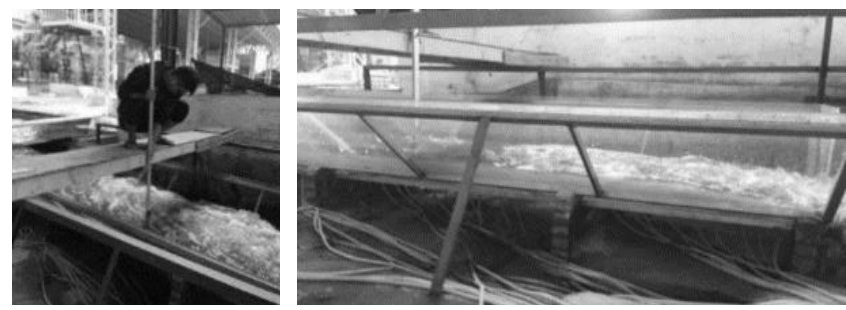

FIGURE 3. Measuring data and hydraulic jump with $Q=1181 \cdot \mathrm{s}^{-1}$ and $F r_{D 1}=4.19$

used to create flow stability at the end of the experimental model.

- Control gate (5): Controls the change of water level in the channel (3), creating different cases of the jump.

For each case of the jump in the trapezoidal channel, the values to be collected in the experiment include: the flow rate $(Q)$, the conjugate depths $\left(y_{1}, y_{2}\right)$ and the roller length $\left(L_{r}\right)$. The conjugate depths were determined through a levelling staff (Fig. 3) and a surveying equipment. The roller length $\left(L_{r}\right)$ is measured with a ruler, initially marking the beginning of the jump (the position with $y_{1}$ ), based on the observation of surface roller and the water surface to determine the end of the roller in the hydraulic jump. The experimental values are shown in Tables 2 and 3 . 
Ngoc, N. M., Cuong, P. H., Son, T. T., Nam, N. V., Phong, N. T. (2022). Experimental study of the hydraulic jump length in a smooth trapezoidal channel. Sci. Rev. Eng. Env. Sci., 31 (1), 63-76. DOI 10.22630/srees.2334

TABLE 2. Experimental data range

\begin{tabular}{|l|c|c|c|c|}
\hline Parameter & Symbol & Unit & Max & Min \\
\hline Discharge & $Q$ & $\mathrm{~m}^{3} \cdot \mathrm{s}^{-1}$ & 0.04 & 0.193 \\
\hline Initial depth of hydraulic jump & $y_{2}$ & $\mathrm{~m}$ & 0.03 & 0.093 \\
\hline Secondary depth of hydraulic jump & $y_{1}$ & $\mathrm{~m}$ & 0.141 & 0.396 \\
\hline Upstream Froude number & $F r_{D 1}$ & - & 3.5 & 8.9 \\
\hline Ratio coefficient of side slope and flow depth with bed width & $M$ & - & 0.169 & 0.058 \\
\hline
\end{tabular}

TABLE 3. Data of the hydraulic jump in the trapezoidal channel of bed width $b=55 \mathrm{~cm}$

\begin{tabular}{|l|c|c|c|c|c|}
\hline Value & $\frac{L_{r}}{y_{1}}$ & $M_{1}=\frac{m \cdot y_{1}}{b}$ & $F r_{D 1}$ & $\frac{y_{2}}{y_{1}}$ & $\frac{y_{1}}{y_{2}}$ \\
\hline Maximum & 34.21 & 0.17 & 8.94 & 10.26 & 0.29 \\
\hline Minimum & 14.49 & 0.05 & 3.55 & 3.48 & 0.10 \\
\hline
\end{tabular}

\section{Establishing an empirical equation to determine the roller length of the jump}

\section{Relationship between the jump length and influential factors}

Studying the factors affecting the jump length, MS Excel 2019 software is used to analyze the correlation functions, these relationships are expressed based on the largest $j$ coefficient $R^{2}$. The correlation relationships between the characteristics of the jump are shown as follows.

\section{Effect of the conjugate depths}

According to Figure 4, the correlation between the roller length $\left(L_{r}\right)$ and the height of the jump $\left(y_{2}-y_{1}\right)$ is not high, the coefficient $R^{2}$ is 0.72 .

The height of the jump $\left(y_{2}-y_{1}\right)$ has a relationship with the jump length, this has been shown in some studies of the jump length. This relationship is shown in Figure 5.
The conjugate depths of the jump and the jump length can have a rather deep relationship, which is shown in the empirical equations for the jump length in rectangular and trapezoidal channels.

The relationship between the jump length and the conjugate depth features is shown in Figure 5 and 6.

From the analysis charts (Figs. 5 and 6), it is found that the relationship between the jump length values and the conjugate depth ratio is very close $\left(R^{2}>0.9\right)$, which is also shown in the jump length equations in a prismatic channel. When the equation is established to compute the jump length, the ratio of the conjugate depths is also a necessary and important parameter. The relationship between the ratio $L_{r} / y_{1}$ and $y_{1} / y_{2}$ or $y_{2} / y_{1}$ is a nonlinear function.

A general observation of the relationship between the roller length ratio $\left(L_{\mathrm{r}} / y_{1}\right)$ with the sequent depth ratio in Figures 6 and 7 shows that these relationships are very strong, the coefficient $R^{2}>0.9$. Besides, Figure 5 shows 


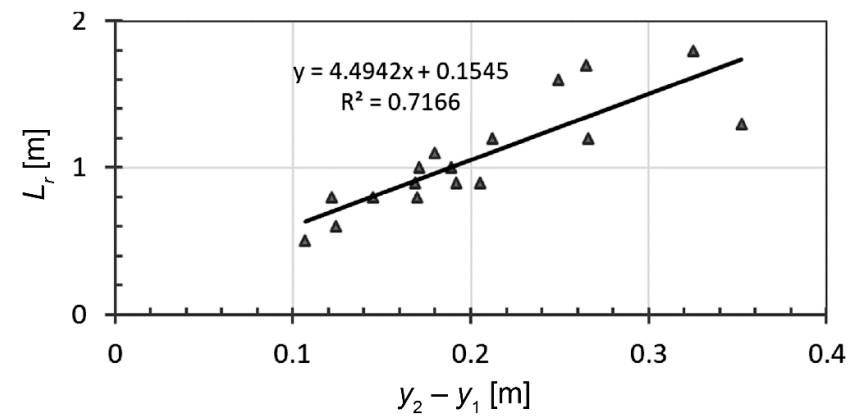

FIGURE 4. Diagram of the relationship between $L_{r}$ and $y_{2}-y_{1}$

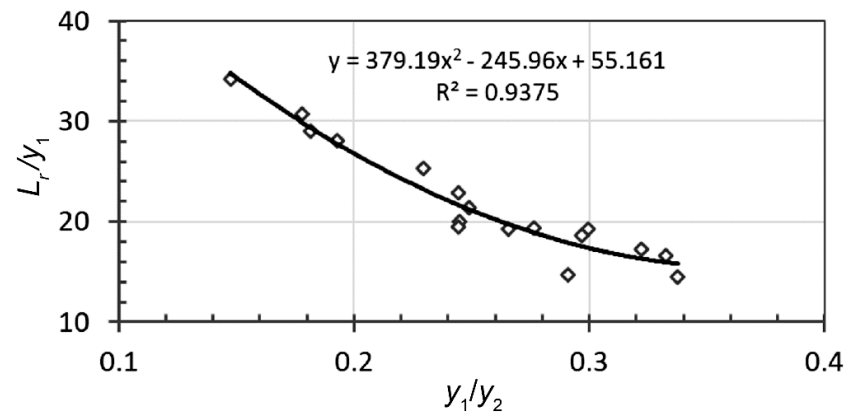

FIGURE 5. Relationship between ratio $L_{r} / y_{1}$ and $y_{1} / y_{2}$

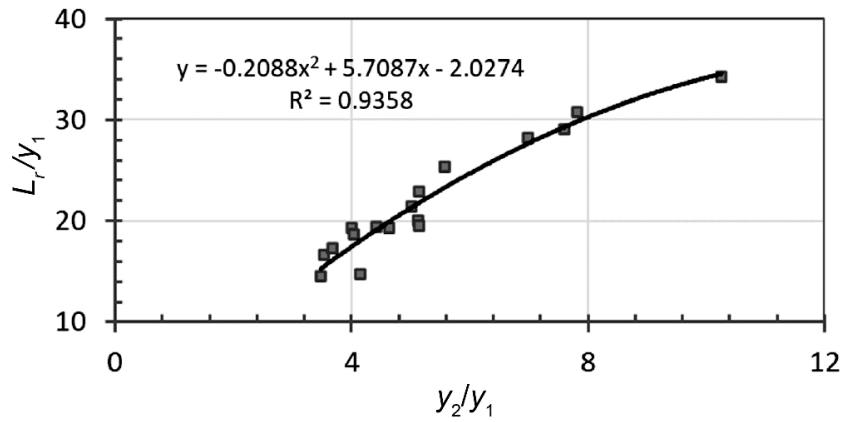

FIGURE 6. Relationship between ratio $L_{r} / y_{1}$ and $y_{2} / y_{1}$ the relationship between the roller length relationship between $\left(L_{r} / y_{1}\right)$ and $\left(\frac{y_{2}-y_{1}}{y_{1}}\right)$
$\left(L_{r}\right)$ and the jump height $\left(y_{2}-y_{1}\right)$ with the is shown as Figure 7 . coefficient $R^{2}=0.7$ (moderate correlation). Therefore, a relationship is to be found with a higher correlation coefficient by combining the above analyzes. As a result of that, the

As shown in Figure 7, the correlation coefficient is very strong, the coefficient $R^{2}$ is very large $\left(R^{2}=0.94\right)$, which shows the close relationship of these factors with each other. 


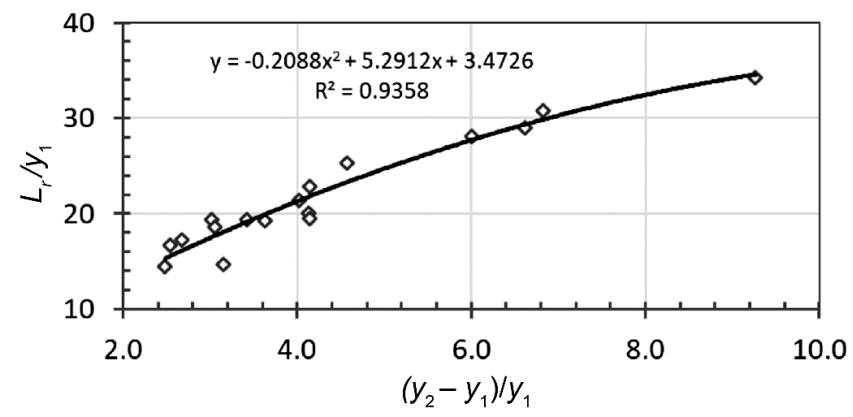

FIGURE 7. Relationship between ratio $L_{r} / y_{1}$ and ratio $\left(y_{2}-y_{1}\right) / y_{1}$

Relationship between the roller length and the inflow Froude number

The inflow Froude number is an important parameter, from Equation (6) it can be seen that the Froude number is closely related to the jump length.

From the experimental data of the physical model, we have the following relationship presented in Figure 8.

The relationship between the ratio $\left(L_{r} / y_{1}\right)$ and the inflow Froude number $\left(F r_{D 1}\right)$ according to Figure 8 is shown that the coefficient $R^{2}$ is very strong $\left(R^{2}=0.93>0.9\right)$. Thus, the relationship between the jump length and Froude number tends to converge strongly, which is consistent with some equations for calculating the jump length in prismatic channels and tends to be similar to studies in the trapezoidal channel of Kateb (2014), Siad (2018), Al-Fatlawi, Al-Mansori and Othman (2020).

\section{Relationship between the roller length and Reynolds number}

The Reynolds number is an important parameter in the study of the flow, the Reynolds number characterizes inertial and viscous forces. The Reynolds number is also a characteristic parameter for the flow state. This relationship is expressed in Figure 9.

As shown in Figure 9, the relationship between the jump length and Reynolds number is wide dispersion. Therefore, establishing the relationship between the jump length and the

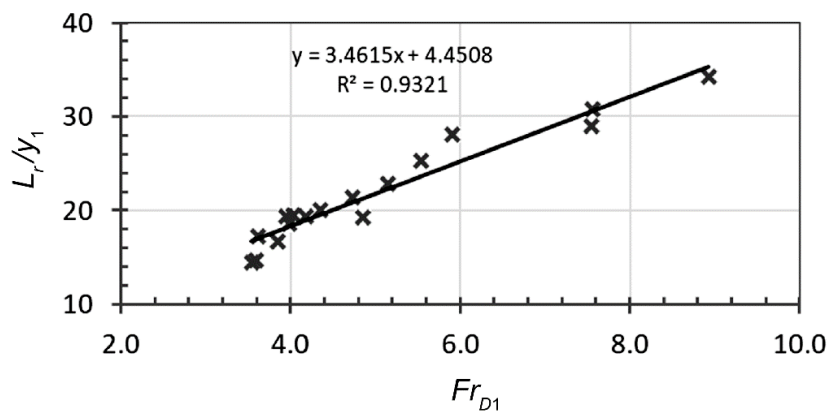

FIGURE 8. The graph of the relationship between the ratio $L_{r} / y_{1}$ and the inflow Froude number $\left(F r_{D 1}\right)$ of the jump 


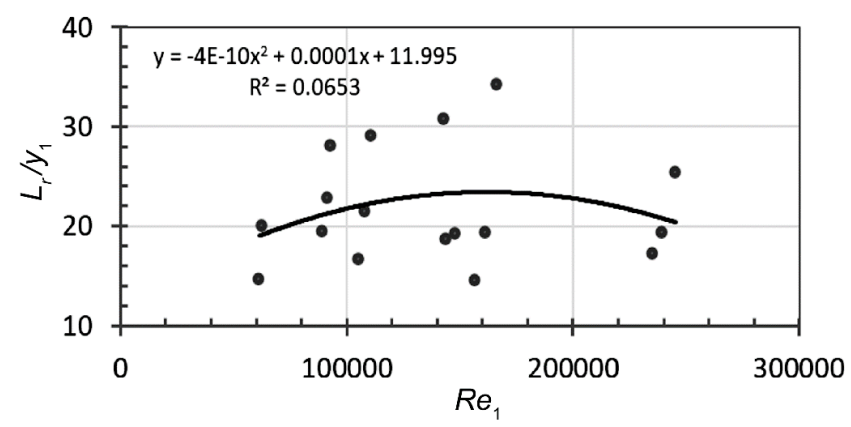

FIGURE 9. Relationship between the ratio $L_{r} / y_{1}$ and the inflow Reynolds number

Reynolds number is not very meaningful and it is difficult to establish the effect of the Reynolds number on the jump length. This parameter is removed when analyzing the influencing factors in the jump length equation.

\section{Relationship between the length}

and the energy of the hydraulic jump

The jump length and the hydraulic jump energy have a close relationship, which is clearly shown in the empirical equations for the jump length on the prismatic channel. The authors used the energy factor to determine the empirical jump length equation.

Comprehensively, to evaluate the factors affecting the jump length, it is necessary to define the relationship between the jump length and the hydraulic jump energy. This relationship is shown in Figures 10 and 11.

As the result in Figures 10 and 11, it shows that the jump length is closely related to the hydraulic jump energy, the coefficient $R^{2}$ is very strong $\left(R^{2}>0.9\right)$. The relationship between the jump length and the energy has been demonstrated in the study of Ohtsu (1976). This factor should be included in the jump length equation.

\section{Effecting the second depth on the roller length of the hydraulic jump}

From the above, it is shown that the ratio between $L_{r} / y_{1}$ is closely correlated with other hydrodynamic factors of the jump. Consider-

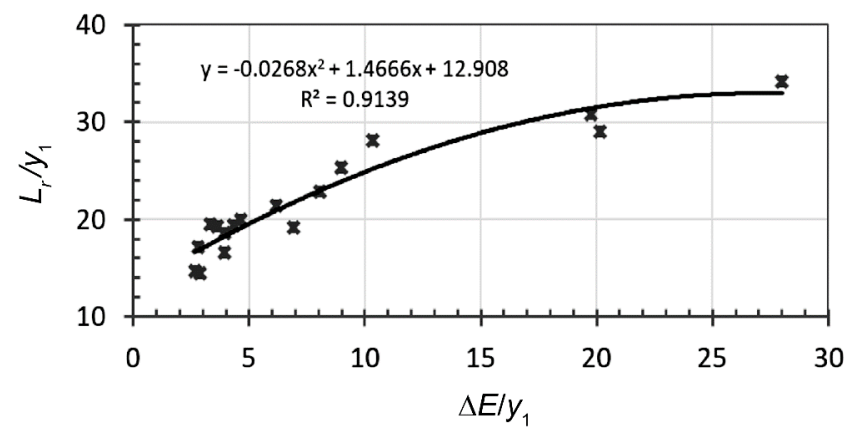

FIGURE 10. Relationship between ratio $L_{r} / y_{1}$ and ratio $\Delta E / y_{1}$ 


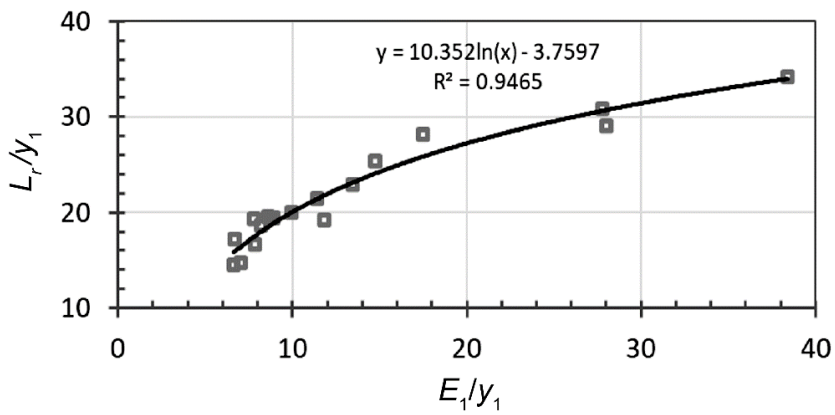

FIGURE 11. Relationship between ratio $L_{r} / y_{1}$ and ratio $E_{1} / y_{1}$

ing further the relationship between the jump length and the downstream hydraulic jump depth $\left(y_{2}\right)$.

As shown in Figures 12, 13 and 14, the coefficients $R^{2}$ is very small $\left(R^{2}<0.5\right)$, the correlation is weak, the graph also shows the dispersion of experimental points. So, this relationship is not suitable to establish the jump length equation.

From the analysis of empirical relationships, it shows that Equation (6) clearly presents the factors affecting the jump length,

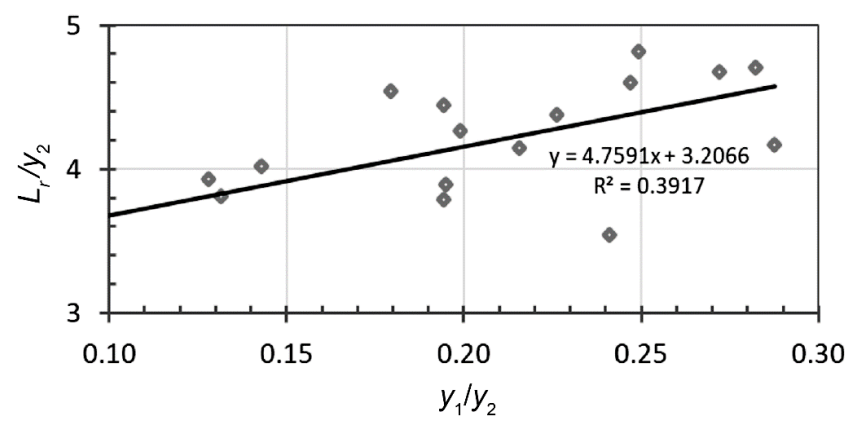

FIGURE 12. Relationship between the ratio $L_{r} / y_{2}$ and $y_{1} / y_{2}$

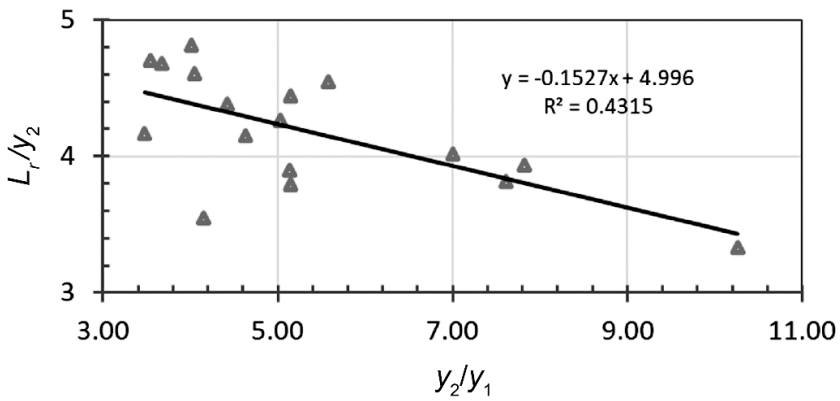

FIGURE 13. Relationship between the ratio $L_{r} / y_{2}$ and $y_{2} / y_{1}$ 


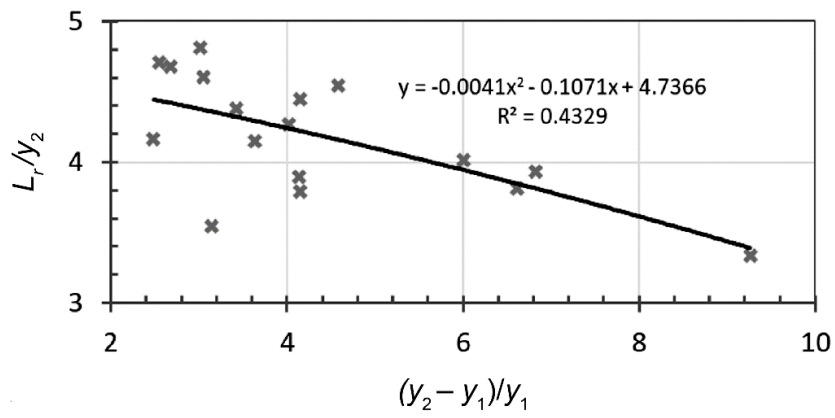

FIGURE 14. Relationship between the ratio $L_{r} / y_{2}$ and the ratio $\left(y_{2}-y_{1}\right) / y_{1}$

thereby determining the basis for establishing empirical equations about the jump length in the smooth trapezoidal channel.

\section{Establishing empirical equations}

Based on the analysis of the relationship between the influential factors and the jump length, the measured data on the experimental model and the structure of the existing equations were used to establish the roller length equations in the trapezoidal channel. Analyzing data and to build some empirical equations in Table 4.

\section{Analyzing and evaluating the new experimental equations}

\section{Analyzing the observed data}

Evaluating the experimental equations $\left(L_{r}\right)$ according to strong statistical indicators (MEA, MSE, RMSE, MAPE and $R^{2}$ ) for the experimental data is presented in Table 5 .

The observation of Table 5 shows that the coefficients $R^{2}$ of the empirical equations are very strong $\left(R^{2}>0.9\right)$. Evidently, the coefficient $R^{2}$ of the empirical equation $L_{r 4}$ is not the largest $\left(R^{2}=0.97\right)$, but the other sta-

TABLE 4. The empirical roller length of the hydraulic jump

\begin{tabular}{|l|l|c|c|}
\hline Symbol & Equation & $R^{2}$ & Characteristics \\
\hline$L_{r 1}$ & $\frac{L_{r}}{y_{1}}=2.285+2.956 F r_{D 1}+1.896 \frac{y_{2}-y_{1}}{y_{1}}-0.142 \frac{\Delta E}{y_{1}}$ & 0.977 & - \\
\hline$L_{r 2}$ & $L_{r}=1.850(1.716+10.872 M)\left(y_{2}-y_{1}\right)$ & 0.903 & Silvester (1964) \\
\hline$L_{r 3}$ & $\frac{L_{r}}{y_{1}}=4.952 F r_{1}^{0.986}+1.679$ & 0.962 & $\begin{array}{c}\text { Rajaratnam \& Subramanya } \\
(1968), \text { Kateb (2014), Siad (2018) }\end{array}$ \\
\hline$L_{r 4}$ & $\frac{L_{r}}{y_{1}}=6.607\left(\frac{y_{2}}{y_{1}}\right)^{0.276}\left(1-\frac{A_{1}^{2}}{A_{2}^{2}}\right) F r_{D 1}^{0.484}$ & 0.970 & - \\
\hline
\end{tabular}


tistical indicators are in best level $(M E A=$ $=0.047, M S E=0.004, R M S E=0.062$ and $M A P E=4.8 \%$ ), so this equation will be used to analyze the data of Wanoschek and Hager (1989).

TABLE 5. Statistical indicators

\begin{tabular}{|l|c|c|c|c|c|}
\hline Equation & $M E A$ & $M S E$ & $R M S E$ & $R^{2}$ & $M A P E[\%]$ \\
\hline$L_{r 1}$ & 0.098 & 0.015 & 0.121 & 0.977 & 10.395 \\
\hline$L_{r 2}$ & 0.079 & 0.012 & 0.111 & 0.903 & 8.138 \\
\hline$L_{r 3}$ & 0.186 & 0.043 & 0.207 & 0.962 & 18.333 \\
\hline$L_{r 4}$ & 0.047 & 0.004 & 0.062 & 0.970 & 4.846 \\
\hline
\end{tabular}

\section{Analyzing the testing data}

Using data from the experiment of Wanoschek and Hager (1989) with the bed width $0.2 \mathrm{~m}$ and side slope $1: 1$ to test the proposed equation with the case of Froude numbers from 4.0 to 9.0 and some data with condition $y_{1}<3 \mathrm{~cm}$ is to be removed.

The statistical analysis between the measured and calculated values is in Table 5 .

As shown in Table 6, the calculation results of the empirical equation $L_{r 4}$ for the test- ing data gave good results, in which the coefficients $R^{2}$ are strong $\left(R^{2} \approx 0.9\right)$, other statistical indicators are also smaller than 0.11 and the $M A P E$ is $6.8 \%$. This shows that the empirical equation $L_{r 4}$ is very suitable in calculating the jump length for the trapezoidal channel.

TABLE 6. Statistical indicators by Wanoschek and Hager (1989)

\begin{tabular}{|l|c|c|c|c|c|}
\hline Equation & $M E A$ & $M S E$ & $R M S E$ & $R^{2}$ & $M A P E[\%]$ \\
\hline$L_{r 4}$ & 0.097 & 0.013 & 0.113 & 0.892 & 6.844 \\
\hline
\end{tabular}

The predicted and measured values of the study are very concentrated and maximum error within $10 \%$ (Fig. 15).

Applying the empirical equation $L_{r 4}$ to the data of Wanoschek and Hager (1989), has shown the agreement between the measured and calculated values, the largest error is $12 \%$.

In general, as the test results in Figures 15 and 16 show that the empirical equation $L_{r 4}$ has good reliability when calculating the hydraulic jump roller length in the trapezoidal channel. The calculation data error is about $\pm 10 \%$ compared to the observed values.

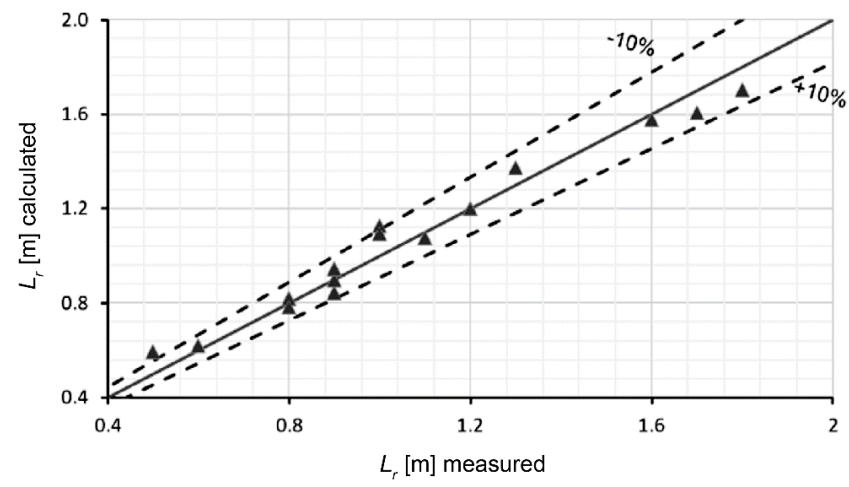

FIGURE 15. Comparison between the observed values and computed by the empirical equation $L_{r 4}$ 


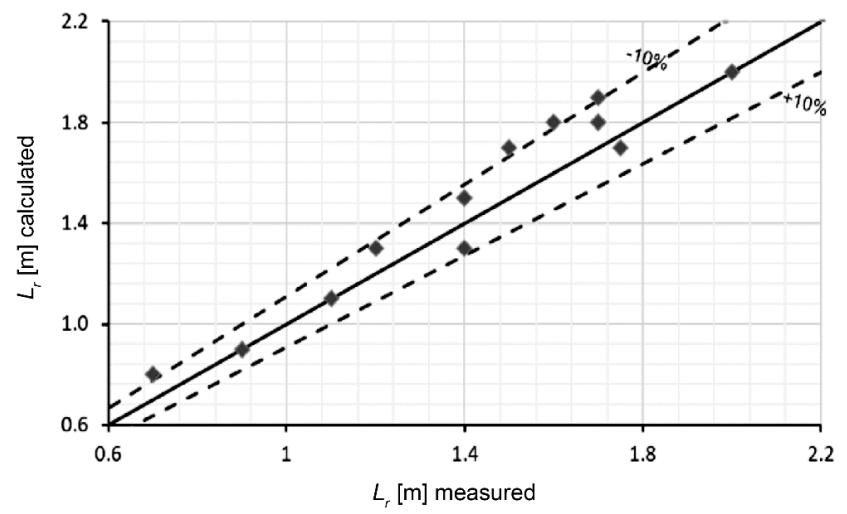

FIGURE 16. Comparison between the observed values (Wanoschek \& Hager, 1989) of the testing data and those computed by the empirical equation $L_{r 4}$

\section{Conclusions}

Research on determining the roller length in the trapezoidal channel plays an important role in the design of constructions, which uses the phenomenon of the jump. In practice, the jump length is often not determined by theoretical equations, but through experimentation to establish the equations.

In this study, empirical equations to determine the jump length in trapezoidal channel has been established to serve as a basis for studying the factors affecting the jump length.

Since then, statistically, the factors affecting the jump length have been drawn, and through the experimental data of the physical model, the correlation between the roller length and the influential factors have been found. It is relatively shown that close relationship between the hydraulic jump roller length and influential factors were determined. The correlation coefficient of the jump length with the inflow Froude number is $R^{2}=0.935$, with the jump height $\left(y_{2}-y_{1}\right)$ is $R^{2}=0.904$, with the conjugate depth ratio $\left(y_{1} / y_{2}\right.$ and $\left.y_{2} / y_{1}\right)$ of $R^{2}=0.9596$ and
$R^{2}=0.972$, respectively, with the energy dissipation ratio $\left(\Delta E / y_{1}\right)$ is $R^{2}=0.915$.

Based on the multivariable nonlinear analysis for the factors affecting the jump length, the empirical equation $L_{r 4}$ has been established based.

The results of the analysis of statistical indicators show that the empirical equation $L_{r 4}$ has the best indicators compared to the remaining equation, such as the coefficient $R^{2}=0.97$ (very strong correlation). The evaluation criteria such as MEA, MSE, RMSE, have values of $0.047,0.004$ and 0.062 , respectively, which is the smallest in comparison to all equations, especially the mean absolute percentage error is very small $(M A P E=4.8 \%)$. Thus, the empirical equation $L_{r 4}$ has great efficiency in calculating the jump length in the trapezoidal channel.

The result of testing with data of Wanoschek and Hager (1989) also showed that the calculation efficiency of the formula is very strong: the $R^{2} \approx 0.9$ (strong correlation); other statistical indicators are also very close to zero $(M E A=0.097, M S E=0.013)$; the $M A P E$ is very small $(6.8 \%)$. 
In this study, it is proposed to use the empirical equation $L_{r 4}$ to calculate the hydraulic jump roller length in a horizontal trapezoidal channel in the case with the side slop $1: 1$ and the inflow Froude number from 4.0 to 9.0 (the steady jump). From there, it will serve as a basis for the design of the energy dissipation construction or the other constructions using the hydraulic jump phenomenon.

\section{References}

Afzal, N. \& Bushra, A. (2002). Structure of the turbulent hydraulic jump in a trapezoidal channel. Journal of Hydraulic Research, 40 (2), 205-214.

Al-Fatlawi, T. J., Al-Mansori, N. J. \& Othman, N. Y. (2020). Laboratory study of stilling basin using trapezoidal bed elements. Scientific Review Engineering and Environmental Sciences, 29 (4), 409-420.

Chow, V. T. (2009). Open channel hydraulic. Caldwell: The Blackburn Press.

Fatehi Nobarian, B., Hajikandi, H., Hassanzadeh, Y. \& Jamali, S. (2019). Experimental and analytical investigation of secondary current cells effects on hydraulic jump characteristics in trapezoidal channels. Tecnología $y$ ciencias del agua, 10 (3), 190-218.

Frank, M. W. (2016). Fluid mechanics. New York: McGraw-Hill Education.

Giglou, A. N., Giglou, T. N. \& Minaei, A. (2013). Analytical analysis of the hydraulic jump roller length in open channel. Life Science Journal, 10 (6s), 669-673.

Kateb, S. (2014). Etude theorique et experimentale de quelques types de ressauts hydrauliques dans un canal trapezoidal [Theoretical and experimental study of some types of hydraulic jumps in a trapezoidal channel] ( $\mathrm{PhD}$ thesis). The University of Mohamed Khider Biskra, Biskra.

Movahed, S. A. M., Mozaffari, J., Davoodmaghami, D. \& Akbari, M. (2018). A semi-analytical equation to estimate hydraulic jump length. Periodica Polytechnica Civil Engineering, 62 (4), 1001-1006.
Ohtsu, I. (1976). Free hydraulic jump and submerged hydraulic jump in trapezoidal and rectangular channels. Proceedings of the $\mathrm{Ja}$ pan Society of Civil Engineers, 1976 (246), $57-72$.

Palermo, M. \& Pagliara, S. (2017). A review of hydraulic jump properties on both smooth and rough beds in sloping and adverse channels. Acta Scientiarum Polonorum. Formatio Circumiectus, 16 (1), 91-105.

Posey, C. J. \& Hsing, P. S. (1938). Hydraulic jump in trapezoidal channel. Engineering News Record, 121, 797-798.

Rajaratnam, N. \& Subramanya, K. (1968). Profile of the hydraulic jump. Journal of the Hydraulics Division, 94 (3), 663-674.

Siad, R. (2018). Hydraulic jump in a sharply widened trapezoidal channel (doctoral thesis). The University of Mohamed Khider Biskra, Biskra.

Silvester, R. (1964). Hydraulic jump in all shapes of horizontal channels. Journal of the Hydraulics Division, 90 (1), 23-55.

Wanoschek, R. \& Hager, W. H. (1989). Hydraulic jump in trapezoidal channel. Journal of Hydraulic Research, 27 (3), 429-446.

\section{Summary}

Experimental study of the hydraulic jump length in a smooth trapezoidal channel. The paper showed the result of investigation of the hydraulic jump length in a trapezoidal channel. In this study, the basic factors that affect the length $\left(L_{j}\right)$ and roller length $\left(L_{r}\right)$ of the hydraulic jump were investigated by a physical trapezoidal channel's model. The experiment carried out in purpose to establish a new empirical equation for calculating the roller length $\left(L_{r}\right)$ of the jump in the horizontal trapezoidal channel with the upstream Froude number 4.0 to 9.0 (the steady jump). The hydraulic characteristics of forced jump were measured and statistically calculated using MS Excel software. The results of data analysis showed 
Ngoc, N. M., Cuong, P. H., Son, T. T., Nam, N. V., Phong, N. T. (2022). Experimental study

that the MAPE was relatively small $(<5 \%)$, and $R^{2}>0.9$ (strong correlation between predicted and observed values) and other statistical indicators are less than $0.1(M S E=0.004$, $R M S E=0.062, M E A=0.047) . \quad$ Therefore, the equation found could be appropriated and applied to calculate characteristics of hydraulic jump trapezoidal channel. 